\title{
La difícil salvaguarda del patrimonio mundial en la globalización
}

\author{
Daniel Martínez Castizo | historiador y antropólogo
}

URL de la contribución <www.iaph.es/revistaph/index.php/revistaph/article/view/4094>

A estas alturas, nadie puede negar que la eufórica revolución económica nacida en los noventa del siglo pasado haya generado un sinfín de externalidades negativas -políticas, económicas, medioambientales, sociales y también culturales- en todo el mundo.

En ese sentido, cualquier debate que plantee cómo prevenir y abordar los enormes daños al patrimonio mundial debe introducir, como elemento clave que permita entender por qué se producen, el contexto político y económico de la globalización.

Si bien los inconvenientes de la globalización capitalista ya han sido -y lo siguen siendo hoy día- objeto de debates y análisis en foros y organismos internacionales como la UNESCO (homogeneización, destrucción y mercantilización cultural y natural), hasta el momento las conclusiones y actuaciones se han tornado en sectoriales (con un organismo o medida creado al uso para tratar cada problema de forma aislada) y paliativas (actuaciones correctivas que no se adentran en cuestionar el modelo económico).

Respondiendo a este modelo, la Organización de las Naciones Unidas para la Educación, la Ciencia y la Cultura (UNESCO), casi desde su creación, ha llevado a cabo recomendaciones (34), convenciones (30) y declaraciones (13), con el objetivo de garantizar la salvaguarda del patrimonio mundial. En ellas se apuntan al respeto de la diversidad cultural; la necesaria conservación de los bienes con los que estos pueblos se identifican (creación de la Lista del Patrimonio Mundial); así como la articulación de medidas para su protección (campañas de Abu Simbel, Venecia, Borobudur, Mohenjo-Daro); y, por supuesto, la consideración de su destrucción como una vulneración de los derechos humanos (sentencia de la Corte Penal Internacional sobre la destrucción del antiguo mausoleo en Tombuctú).
La situación actual es, pese a todas las actuaciones efectuadas desde mediados de siglo XX, de riesgo sobre el patrimonio mundial con tanta o más fuerza que hace setenta años. Esto no quiere decir que las medidas no hayan sido acertadas sino que, más bien, han partido de un postulado erróneo a la hora de enfocar el principal problema, pues se tiende a considerar estas externalidades como una consecuencia inevitable con la que hay que convivir hasta que la política encuentre una solución.

Pero ocurre que, en la globalización, la política se encuentra en manos de los mercados y, por tanto, nunca van a aparecer soluciones sino más bien medidas tendentes a la expansión y el crecimiento económico. Dicho de otra forma, solo se pueden esperar más y nuevos problemas sobre los bienes culturales y naturales.

Ahora bien y, como decíamos antes, los factores que causan daños o ponen en riesgo el patrimonio mundial (conflictos bélicos, terrorismo y desastres naturales) no pueden ser interpretados como un fenómeno aislado, sino que deben entenderse como fruto de la globalización y, por tanto, que forman parte de un mismo conjunto de intereses políticos y económicos que dan lugar, en todas partes, a la potenciación de los factores que amenazan con la destrucción de dichos bienes.

Es por ello que las cumbres de la Tierra (Estocolmo, Río de Janeiro, Johannesburgo o Río+20) han venido a reconocer década tras década -a través de un discurso no muy crítico pero fuertemente cuestionado- el potencial destructor de la globalización desde el punto de vista político, económico, medioambiental, social y cultural. Por ese motivo, a continuación de cada gran cumbre, le ha acompañado una Convención de la UNESCO (ambas últimas en París), en la que se han integrado los nuevos principios con los que hacer frente a los problemas y factores que atentan contra el patrimonio. 
a debate Patrimonio, terrorismo y desastres naturales ¿Cómo prevenir y abordar los enormes daños al patrimonio cultural mundial?

| coordinan Francisco Javier López Morales, Francisco Vidargas

De esta forma, solo si aplicamos el contexto político y económico de la globalización, podemos entender el fenómeno de la destrucción del patrimonio en Oriente Medio (Irak, Afganistán o Siria), como una de las consecuencias, entre otras muchas, de la "guerra contra el terror" iniciada por las potencias occidentales después del 11-S, y no como una cuestión exclusiva del terrorismo internacional (ISIS y Al-Qaeda), imposible de solucionar.

Así mismo, también se explica que, en 2017, EUA abandonase el "Acuerdo de París contra el cambio climático" $y$, acto seguido, también la UNESCO. Pese a que algunos pueden ver en ello un acontecimiento fruto de un presidente muy particular, la realidad es que forma parte del rechazo a cualquier organismo que plantee algún atisbo de cuestionamiento al estatus quo internacional. Y es que, EUA, defensor de la globalización, no puede abandonar el Acuerdo de París sin salir del organismo internacional que intenta paliar las externalidades que ponen en peligro el patrimonio, es decir, la UNESCO.

En resumidas cuentas y, pese a que la primera potencia mundial -máximo exponente de la globalización- tome decisiones que ayudan poco a solucionar los problemas medioambientales, económicos y sociales que ponen en riesgo el patrimonio mundial, la UNESCO y sus Estados miembros deben intensificar, con la misma intensidad con la que las amenazas se manifiestan, las medidas paliativas que durante décadas se llevan ejecutando. Ello nos llevaría, como la historia reciente nos ha demostrado, a amortiguar, que no acabar, con los potenciales factores de riesgos que atentan contra estos bienes.

Mientras tanto y, como la medida más eficaz para salvaguardar el patrimonio mundial, cabe la posibilidad de consensuar, desde el multilateralismo internacional, actuaciones dirigidas hacia la construcción de alternativas socioeconómicas a la globalización. Un sistema que, al fin y a la postre, es la fuente y causa principal de todos los enormes daños que los bienes culturales y naturales vienen sufriendo en todo el mundo.

\section{BIBLIOGRAFÍA}

- CONVENCIÓN sobre la protección del patrimonio mundial, cultural y natural [en línea] UNESCO, París del 17 de octubre al 21 de noviembre de 1972 <http://whc.unesco.org/archive/ convention-es.pdf> [Consulta: 14/12/2017]

- DECLARACIÓN de la UNESCO relativa a la destrucción intencional del patrimonio cultural [en línea] UNESCO, 17 de octubre de $2003<$ http://portal.unesco.org/es/ev.php-URL ID=17718\&URL_DO=DO_TOPIC\&URL_SECTION=201.html> [Consulta: 14/12/2017]

- LIST of World Heritage in Danger, UNESCO <http://whc. unesco.org/en/danger/> [Consulta: 13/12/2017]

- MONCADA, A. (2007) Para entender la globalización. Intersticios, Volumen 1 (2), 2007, pp. 255-256

- QUEROL, M. A. (2012) La UNESCO: El Patrimonio Mundial. En QUEROL, M. A. Manual de Gestión del Patrimonio Cultural. Madrid: AKAL, 2012, pp. 418-439

- UNESCO and Partners stand against Cultural Cleansing and Violent Extremism [en línea] <https://en.unesco.org/news/ unesco-and-partners-stand-against-cultural-cleansing-andviolent-extremism> [Consulta: 14/12/2017]

- WAGNER. M; AUSTIN, N. (2016) La muerte de los sitios de Patrimonio Mundial. Project Syndicate: PS-The World's Opinion Page [en línea] <http://www.mondialisations.org/php/ public/art. php?id=40082\&lan=ES> [Consulta: 13/12/2017] 